\title{
Ruptured Pseudoaneurysm after Gamma Knife Surgery for Vestibular Schwannoma
}

\author{
Mamoru MURAKAmI, ${ }^{1}$ Kentaro KaWARABUKI, ${ }^{2}$ Yasuo InOUE, ${ }^{2}$ and Tsutomu OHTA $^{1}$ \\ ${ }^{1}$ Department of Neurosurgery, Fukuchiyama City Hospital, Fukuchiyama, Kyoto; \\ ${ }^{2}$ Department of Neurosurgery, Maizuru Medical Center, Maizuru, Kyoto
}

\begin{abstract}
Ruptured aneurysms of anterior inferior cerebellar artery (AICA) after radiotherapy for vestibular schwannoma (VS) are rare, and no definite treatment has been established for distal AICA pseudoaneurysms. We describe a 61-year-old man who underwent Gamma Knife surgery (GKS) for left VS. Followup magnetic resonance imaging (MRI) revealed partial regression of the tumor. Twelve years after GKS, he suffered from subarachnoid hemorrhage. Initial angiogram showed no vascular lesions; second left vertebral angiogram, 10 days after admission, demonstrated a pseudoaneurysm in the lateral pontine segment of the left AICA. The proximal portion of the AICA was occluded by a coil. Postoperative MRI revealed an infarction on the left side of the pons and brachium pontis. Although the patient suffered from mild postoperative cerebellar ataxia and facial and abducens nerve palsy, he was discharged 1 month postoperatively requiring no assistance with activities of daily living. Twelve months later, he recovered satisfactorily with a modified Rankin Scale grade of 1, and no recanalization of the aneurysm was found on MR angiography. Endovascular parent artery occlusion for ruptured aneurysms at distal AICA carries the risk of brain stem infarction, but should be considered when no other option is available such as after radiotherapy for VS.
\end{abstract}

Key words: pseudoaneurysm, anterior inferior cerebellar artery, Gamma Knife surgery, vestibular schwannoma

\section{Introduction}

Gamma Knife surgery (GKS) is a well-established form of radiotherapy for vestibular schwannoma. Although radiation-induced vasculopathy is known to be a delayed complication of radiotherapy, aneurysm formation after radiotherapy is rare. We treated a patient with subarachnoid hemorrhage due to a ruptured pseudoaneurysm of the lateral pontine segment of the left anterior inferior cerebellar artery (AICA) 12 years after undergoing GKS for a left vestibular schwannoma. Pseudoaneurysms occur when the wall of a vessel has been compromised by trauma, dissection, surgical injury, or adjacent infection. Six cases of ruptured aneurysms of the AICA after radiotherapy including GKS have previously been described. ${ }^{1-6)}$ Two cases underwent surgical trapping of the aneurysm, and the other five cases, including the current case, underwent endovascular parent artery occlusion (PAO) or internal trapping. According to previous reports, surgical or endovascular treatment carries the risk of brain stem infarction, but the complications did not result in severe disabilities.

Received February 9, 2015; Accepted October 14, 2015

\section{Case Report}

A 61-year-old man presented to our institution with a 6-month history of left-sided hearing impairment. Magnetic resonance imaging (MRI) demonstrated a tumor of the left cerebellopontine angle. The tumor was radiographically diagnosed as a vestibular schwannoma, and the patient underwent GKS at another hospital in June 2002. The tumor margin was covered by the $50 \%$ isodose line, and a dose of $18 \mathrm{~Gy}$ was delivered to the margin (Fig. 1). Annual MRI follow-up after GKS demonstrated partial regression, and the final follow-up image, taken 8 years after GKS, did not show any vascular abnormalities on MR angiography (MRA). Twelve years after GKS, the patient presented with a sudden onset of severe headache and altered level of consciousness. His initial Glasgow Coma Score (GCS) was 5. Diagnostic computed tomography (CT) revealed a diffuse subarachnoid hemorrhage with a predominance of bleeding in the left posterior fossa cisterns (Fig. 2a). The subsequent three-dimensional CT angiogram and conventional angiograms showed no vascular lesions (Fig. 2b). The patient recovered neurologically with conservative therapy, achieving a GCS of 13 by the day after admission. The second conventional angiogram, performed 10 days 


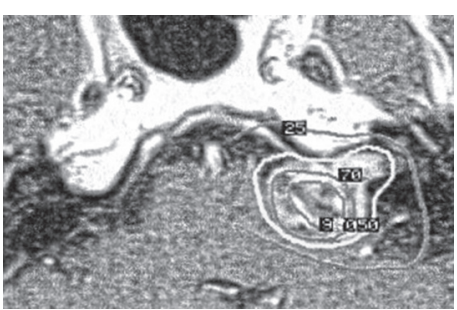

Fig. 1 Dose distribution of planning axial $\mathrm{T}_{1}$-weighted magnetic resonance images with gadolinium for the left vestibular schwannoma. The tumor margin was covered by the $\mathbf{5 0} \%$ isodose line, and $18 \mathrm{~Gy}$ was delivered to the margin (white line).
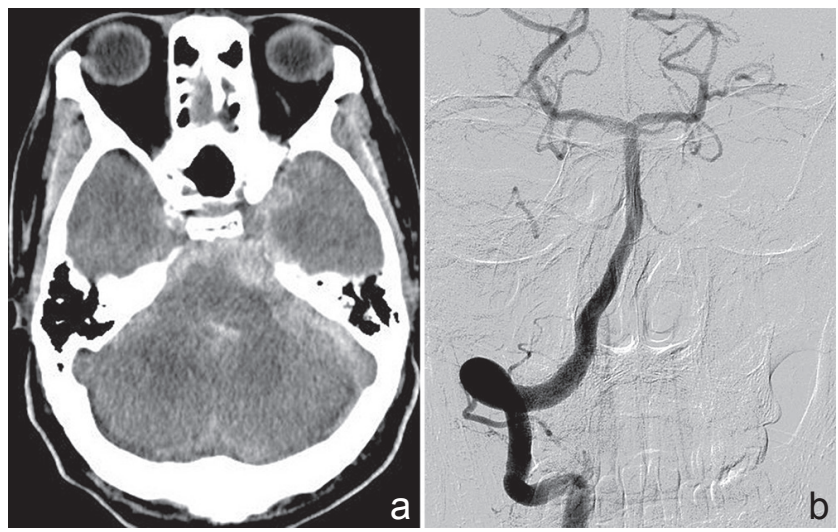

Fig. 2 a: Computed tomography scan on admission revealed diffuse subarachnoid hemorrhage and b: no aneurysms were found on initial conventional angiogram.

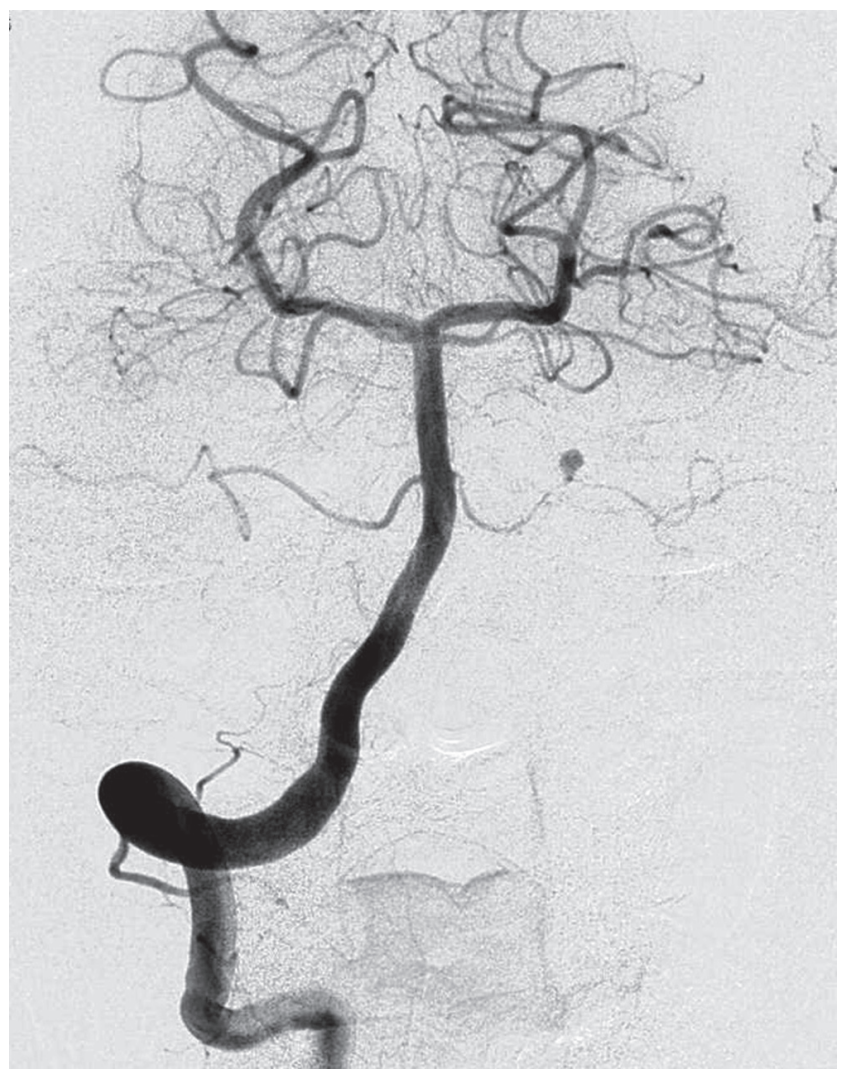

Fig. 3 The second vertebral angiogram, performed 10 days after admission, revealed a round aneurysm of the distal anterior inferior cerebellar artery, which was not located at a branching site.

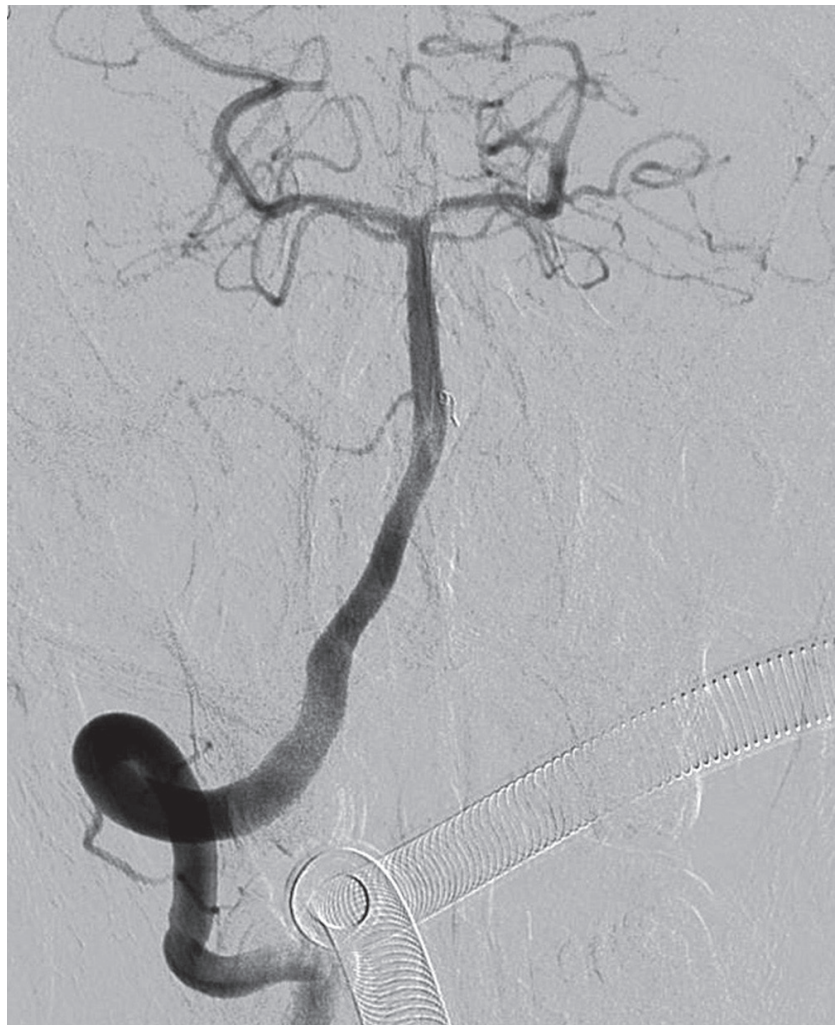

Fig. 4 Angiogram immediately after embolization of the left anterior inferior cerebellar artery.

after admission, demonstrated a round aneurysm $3.0 \mathrm{~mm}$ in diameter at the lateral pontine segment of the left AICA (Fig. 3). The radiation field of the previous GKS included the aneurysm site. The aneurysm was not located at a branching site, suggesting a pseudoaneurysm. On the following day, we performed endovascular coil embolization on the proximal segment of the left AICA. The treatment plan was based on the belief that both the left superior cerebellar artery (SCA) and the left posterior inferior cerebellar artery (PICA) were welldeveloped enough that they would perfuse the regions supplied by the distal portion of the AICA. After a micro-catheter (Marathon, Covidien, Irvine, California, USA) was positioned over the AICA orifice under transient occlusion of the basilar artery using a balloon (HyperGlide $4 \mathrm{~mm} \times 10 \mathrm{~mm}$, Covidien, Irvine, California, USA), the AICA was occluded with one coil (ED coil $1.5 \mathrm{~mm} \times 1 \mathrm{~cm}$, Kaneka, Osaka) (Fig. 4). Anticoagulation therapy via intravenous administration of unfractionated heparin was used to maintain an activated coagulation time over 200 seconds until 24 hours after embolization in order to avoid retrograde thrombosis. Postoperative MRI revealed an infarction on the left side of the pons and brachium pontis (Fig. 5), causing mild cerebellar ataxia, moderate left facial nerve palsy (House-Brackmann Grade III), and abducens nerve palsy. The patient was 
discharged after 1 month of rehabilitation with a modified Rankin Scale (mRS) grade of 2. A conventional angiogram 3 months after endovascular treatment demonstrated no recanalization of the left AICA. Twelve months later, he had recovered satisfactorily with an mRS grade of 1 , and no recanalization of the aneurysm was found on MRA.

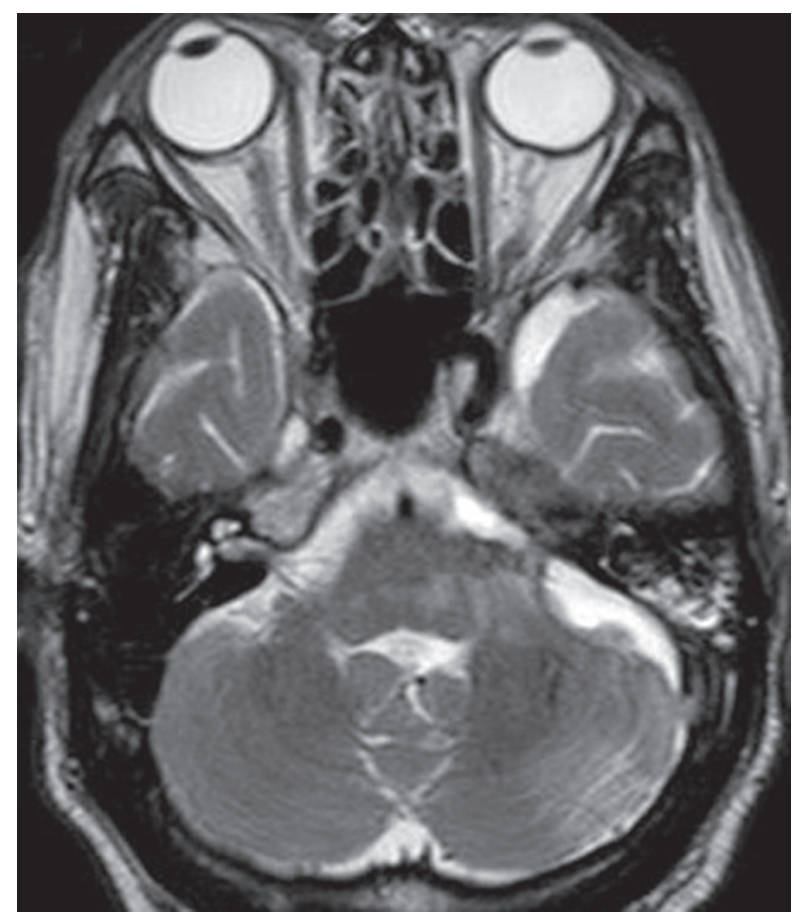

Fig. $5 \mathrm{~T}_{2}$-weighted magnetic resonance imaging revealed an infarction on the left side of the pons and brachium pontis.

\section{Discussion}

We reported on a patient with a ruptured pseudoaneurysm of the distal AICA treated with endovascular PAO. Six cases of ruptured pseudoaneurysms of the AICA after radiotherapy (including GKS) have been described previously (Table 1). ${ }^{1-6)}$ Pseudoaneurysms were diagnosed radiographically in all cases, showing that the distal AICA aneurysms had not developed at branching sites within the irradiated field. In two cases, the pseudoaneurysms were pathologically diagnosed after trapping of the aneurysms via lateral suboccipital craniectomy. Intracranial aneurysms in previously irradiated fields were recently reviewed, including a total of 46 patients with 69 intracranial aneurysms between 1978 and $2013 .{ }^{7}$ Among these reported aneurysms, $83 \%$ were saccular, 9\% were fusiform, and 9\% were pseudoaneurysms. Although the mechanism of pseudoaneurysm formation following radiation has yet to be elucidated, it is hypothesized that the integrity of the parent artery vessel wall is degraded by radiation, making it vulnerable to shear stress and rupture at the weakened point. ${ }^{7)}$ This hypothesis may be supported by pathological examination findings in two cases of AICA pseudoaneurysms, which demonstrated loss of elastic lamina in the aneurysm wall..$^{3,4)}$

No definite treatment has been established for distal AICA pseudoaneurysms. In fusiform or dissecting aneurysms, endovascular or surgical trapping with or without vascular reconstruction is considered the best strategy. Choi et al. reported a case of distal AICA aneurysm at the meatal loop treated with parent artery preservation. ${ }^{8)}$ The dome of the

Table 1 Characteristics of patients with ruptured pseudoaneurysms of the anterior inferior cerebellar artery after stereotactic irradiation for vestibular schwannoma

\begin{tabular}{|c|c|c|c|c|c|c|c|c|}
\hline \multicolumn{2}{|c|}{ Case (year) } & \multirow{2}{*}{$\begin{array}{c}\text { Age/Sex } \\
\text { (at RT) } \\
63 / \mathrm{F}\end{array}$} & \multirow{2}{*}{$\begin{array}{c}\text { Marginal } \\
\text { dose (Gy) } \\
12\end{array}$} & \multirow{2}{*}{$\begin{array}{c}\text { Interval } \\
\text { from RT } \\
\text { to SH (y) }\end{array}$} & \multirow{2}{*}{$\begin{array}{l}\text { Location of aneurysm } \\
\begin{array}{l}\text { Lateral pontine segment } \\
\text { Premeatal portion }\end{array}\end{array}$} & \multirow{2}{*}{$\begin{array}{l}\text { Treatment } \\
\begin{array}{l}\text { Endovascular occlusion } \\
\text { of AICA using coil }\end{array}\end{array}$} & \multirow{2}{*}{$\begin{array}{l}\text { Postoperative } \\
\text { complications } \\
\begin{array}{l}\text { Moderate facial } \\
\text { palsy }\end{array}\end{array}$} & \multirow{2}{*}{$\begin{array}{c}\begin{array}{c}\text { Last mRS } \\
\text { (follow-up) }\end{array} \\
1 \text { (15 mos) }\end{array}$} \\
\hline 1 & Takao et al. 2006 ${ }^{1)}$ & & & & & & & \\
\hline 2 & Park et al. 2009²) & $69 / F$ & 12 & 5 & $\begin{array}{l}\text { Lateral pontine segment } \\
\text { Premeatal portion }\end{array}$ & Failed EVT & None & 0 \\
\hline 3 & Akamatsu et al. $2009^{3)}$ & $75 / F$ & 12 & 8 & $\begin{array}{l}\text { Lateral pontine segment } \\
\text { Meatal portion }\end{array}$ & Trapping of aneurysm & N.D. & N.D. \\
\hline 4 & Yamaguchi et al. 20094) & $67 / \mathrm{F}$ & 25 & 6 & $\begin{array}{l}\text { Lateral pontine segment } \\
\text { Meatal portion }\end{array}$ & Trapping of aneurysm & $\begin{array}{l}\text { Moderate facial } \\
\text { palsy }\end{array}$ & 1 (2 mos) \\
\hline 5 & Sunderland et al. 2014 & $50 / \mathrm{F}$ & $13+12$ & 10 & $\begin{array}{l}\text { Lateral pontine segment } \\
\text { Premeatal portion }\end{array}$ & $\begin{array}{l}\text { Endovascular occlusion } \\
\text { of AICA using coil }\end{array}$ & $\begin{array}{l}\text { Dysarthria/bulbar } \\
\text { palsy }\end{array}$ & N.D. \\
\hline 6 & Mascitelli et al. 2015 & $59 / \mathrm{M}$ & N.D. & 6 & $\begin{array}{l}\text { Lateral pontine segment } \\
\text { Premeatal portion }\end{array}$ & $\begin{array}{l}\text { Endovascular internal } \\
\text { trapping of aneurysm } \\
\text { using n-BCA }\end{array}$ & $\begin{array}{l}\text { Cerebellar and } \\
\text { brachium pontis } \\
\text { infarction }\end{array}$ & N.D. \\
\hline 7 & Present case & $61 / \mathrm{M}$ & 18 & 12 & $\begin{array}{l}\text { Lateral pontine segment } \\
\text { Premeatal portion }\end{array}$ & $\begin{array}{l}\text { Endovascular occlusion } \\
\text { of AICA using coil }\end{array}$ & $\begin{array}{l}\text { Facial \& abducens } \\
\text { palsy, ataxia }\end{array}$ & 1 (12 mos) \\
\hline
\end{tabular}

AICA: anterior inferior cerebellar artery, EVT: endovascular therapy, mos: months, F: female, M: male, mRS: modified Rankin Scale, n-BCA: n-butyl cyanoacrylate, N.D.: not described, RT: radiotherapy, SH: subarachnoid hemorrhage. 
aneurysm was occluded, however, the patient experienced recurrent hemorrhage from the recanalized aneurysm 1 month after embolization.

The AICA is divided into four segments: (1) anterior pontine, (2) lateral pontine, (3) flocculonodular, and (4) cortical, depending on the level of bifurcation of the artery. The lateral pontine segment is further divided into premeatal, meatal, and postmeatal segments, depending on their relationship with the porus of the internal acoustic meatus. ${ }^{9)}$ The treatment strategy should be considered based on the location of the aneurysm. ${ }^{10)}$ Distal AICA aneurysms after radiotherapy for a vestibular schwannoma exhibit dominancy of location at the premeatal loop (Table 1), although distal AICA aneurysms at the meatal loop are the most frequently reported. ${ }^{10)}$ AICA aneurysms at the premeatal segment are so rare that no consensus exists regarding how to best manage these aneurysms. According to Drake et al., two of four cases with proximal AICA aneurysms had poor prognosis, ${ }^{11)}$ and surgical complications are not thought to be less frequent. PAO of the AICA could be a therapeutic alternative, if there is good collateral flow from the collateral SCA and PICA.9.12) Drake et al. reported a case of a fusiform aneurysm at the premeatal AICA treated by proximal AICA clipping without consequence. ${ }^{11)}$ In particular, the residual tumor made surgical trapping more difficult, because the aneurysms were buried by the tumor. ${ }^{3,4)}$ In fact, endovascular PAO or internal trapping without bypass surgery was performed in five of the seven reported cases (Table 1). Occlusion of the AICA results in syndromes related predominantly to softening of the lateral portions of the brain stem and cerebellar peduncles, rather than to involvement of the cerebellar hemisphere, all of which are not identical due to the anatomical variability of the AICA. ${ }^{9)}$ Matsuyama et al. described a case of AICA aneurysm at the anterior pontine segment treated by trapping of the aneurysm with endovascular coiling, with no postoperative pontine infarction. ${ }^{13)}$ When AICA aneurysms occur at the premeatal loop, whether or not PAO of the proximal AICA would lead to a brain stem infarction cannot be predicted, and furthermore, surgical trapping of the aneurysm carries the risk of pontine infarction, even if vascular reconstruction is feasible.

In the present case, we did not advance the microcatheter near the aneurysmal neck due to spastic changes of the AICA, and had no choice but to perform PAO at the proximal portion of the AICA, although PAO should typically be performed just proximal to the aneurysm. Recanalization of the aneurysm was not detected 12 months after treatment, but continuous follow-up will be needed. A flow guiding catheter could potentially be advanced, followed by internal trapping with an injection of n-butyl cyanoacrylate (NBCA). There were two reported cases in which distal AICA aneurysms were treated by endovascular internal trapping using NBCA. Santillan et al. presented a case of AICA aneurysm distal to the meatal loop, ${ }^{14)}$ and Mascitelli et al. described a case with an aneurysm at the lateral pontine segment after resection and stereotactic radiotherapy for a vestibular schwannoma. ${ }^{6)}$ An infarction formed in the cerebellar hemisphere in both cases postoperatively. This underscores the need for further consideration regarding management, but our view is that embolization using liquid material should be avoided.

In conclusion, our findings were similar to those reported previously regarding the high rate of complications with PAO at this location, but that the complications did not result in severe disabilities. Endovascular PAO for ruptured aneurysms at the premeatal AICA carries the risk of brain stem infarction, but should be considered when no other option is available such as after radiotherapy for vestibular schwannoma.

\section{Acknowledgments}

The authors are indebted to Dr. Kondo at the Shin-Suma Hospital Gamma Knife Center for previous information regarding Gamma Knife plan.

\section{Conflicts of Interest Disclosure}

The authors declare that they have no conflict of interest.

\section{References}

1) Takao T, Fukuda M, Kawaguchi T, Nishino K, Ito Y, Tanaka R, Sato M: Ruptured intracranial aneurysm following gamma knife surgery for acoustic neuroma. Acta Neurochir (Wien) 148: 1317-1318; discussion 1318, 2006

2) Park KY, Ahn JY, Lee JW, Chang JH, Huh SK: De novo intracranial aneurysm formation after Gamma Knife radiosurgery for vestibular schwannoma. J Neurosurg 110: 540-542, 2009

3) Akamatsu Y, Sugawara T, Mikawa S, Saito A, Ono S, Takayama K, Jokura H, Seki H: Ruptured pseudoaneurysm following Gamma Knife surgery for a vestibular schwannoma. J Neurosurg 110: 543-546, 2009

4) Yamaguchi S, Kato T, Takeda M, Ikeda H, Kitamura K: Ruptured distal anterior inferior cerebellar artery aneurysm following stereotactic irradiation for vestibular schwannoma: case report. Neurol Med Chir (Tokyo) 49: 202-205, 2009

5) Sunderland G, Hassan F, Bhatnagar P, Mitchell P, Jayakrishnan V, Forster D, Mendelow AD: Development of anterior inferior cerebellar artery pseudoaneurysm after gamma knife surgery for vestibular schwannoma. A case report and review of the literature. Br J Neurosurg 28: 536-538, 2014

6) Mascitelli JR, McNeill IT, Mocco J, Berenstein A, DeMattia J, Fifi JT: Ruptured distal AICA pseudoaneurysm presenting years after vestibular schwannoma resection and radiation. J NeuroIntervent Surg pii, 2015

7) Nanney AD, El Tecle NE, El Ahmadieh TY, Daou MR, Bit Ivan EN, Marymont MH, Batjer HH, Bendok BR: Intracranial aneurysms in previously irradiated fields: literature review and case report. World Neurosurg 81: 511-519, 2014 
8) Choi CH, Cho WH, Choi BK, Lee SW: Rerupture following endovascular treatment for dissecting aneurysm of distal anterior inferior cerebellar artery with parent artery preservation: retreatment by parent artery occlusion with Guglielmi detachable coils. Acta Neurochir (Wien) 148: 363-366; discussion 366, 2006

9) Rhoton AL: The cerebellar arteries. Neurosurgery 53, 461-500, 2003

10) Gi H, Inoha S, Uno J, Ikai Y, Koga H, Yamaguchi S, Nagaoka S: [Four cases of direct surgery for anterior inferior cerebellar artery aneurysms]. No Shinkei Gaka 35: 571-578, 2007 (Japanese)

11) Drake CG, Peerless SJ, Hernesniemi J: Surgery of Vertebrobasilar Aneurysms: London, Ontario Experience on 1,767 Patients. New York, Springer-Verlag, 1996

12) Peluso JP, van Rooij WJ, Sluzewski M, Beute GN: Distal aneurysms of cerebellar arteries: incidence, clinical presentation, and outcome of endovascular parent vessel occlusion. AJNR Am J Neuroradiol 28: 1573-1578, 2007

13) Matsuyama T, Okuchi K, Norimoto K, Ueyama T: Ruptured dissecting anterior inferior cerebellar artery aneurysm-case report. Neurol Med Chir (Tokyo) 42: 214-216, 2002

14) Santillan A, Gobin YP, Patsalides A, Riina HA, Rosengart A, Stieg PE: Endovascular management of distal anterior inferior cerebellar artery aneurysms: Report of two cases and review of the literature. Surg Neurol Int 2: 95, 2011

Address reprint requests to: Mamoru Murakami, MD, Department of Neurosurgery, Fukuchiyama City Hospital, 231 Atsunaka-machi, Fukuchiyama, Kyoto 620-8505, Japan. e-mail: mmamoru0125@fukuchiyama-hosp.jp 